\title{
Pengaruh Letak Telur pada Mesin Tetas terhadap Persentase Daya Hidup Embrio, Lama Menetas dan Gagal Menetas
}

\author{
Putri Lestari $^{1}$, Pradipta Bayuaji Pramono ${ }^{1 *}$, Mikael sihite ${ }^{1}$ \\ ${ }^{1}$ Program Studi Peternakan, Fakultas Pertanian, Universitas Tidar \\ Jl. Kapten Suparman No. 39, Potrobangsan, Kec. Magelang Utara, Kota Magelang, Jawa Tengah \\ *Corresponding author: p.bayuaji.p@untidar.ac.id
}

\begin{abstract}
Abstrak
Letak telur merupakan posisi penempatan telur dalam mesin tetas pada bagian rak atas, tengah dan bawah. Penelitian ini bertujuan untuk mengetahui perbedaan letak telur dalam mesin tetas terhadap daya hidup embrio, lama menetas dan gagal menetas telur ayam strain Ross. Penelitian dilaksanakan pada bulan Januari 2021 di PT. Super Unggas Jaya Unit Hatchery Solo, Jawa Tengah. Menggunakan 2.700 butir telur ayam strain Ross dengan umur induk 43-45 minggu. Rancangan percobaan menggunakan rancangan acak lengkap yang terdiri atas 3 perlakuan dan 5 ulangan. Perlakuan terdiri dari letak telur bagian rak atas, tengah dan bawah dengan jumlah telur 180 setiap ulangan. Hasil penelitian ini memperoleh rata-rata daya hidup embrio telur ayam strain Ross $97,68 \%$, lama menetas 475,59 jam dan gagal menetas sebesar $8,48 \%$. Suhu yang dihasilkan pada penelitian adalah $36,88-36,97^{\circ} \mathrm{C}$ dan kelembapan sebesar 68,16-68,42\%. Berdasarkan analisis keragaman menunjukkan bahwa pengaruh letak telur tidak berbeda nyata $(\mathrm{P}>0,05)$ terhadap daya hidup embrio, lama menetas dan gagal menetas. Kesimpulan dari penelitian ini yaitu perbedaan letak telur dalam mesin tetas menyediakan panas yang optimal sehingga suhu dan kelembapan yang dihasilkan tersebar secara merata.
\end{abstract}

Kata kunci: Daya hidup embrio, Gagal menetas, Lama menetas, Letak telur

\begin{abstract}
Egg layout is the position of placing eggs in the incubator on the top, middle and bottom shelves. This study aims to determine the difference of eggs position in the incubator produced different temperature and humidity, so that it effects on survival rate of embryo, duration of hatching and unhatched eggs chicken Ross. The research was carried out in January 2021 at PT. Super Poultry Jaya Unit Hatchery Solo, Central Java. Using 2700 strain Ross chicken eggs with brood stock aged 43-45 weeks. The experimental design of the completely randomized design was applied consisting of 3 treatments and 5 replications. The treatments were eggs position on the top, middle and bottom shelves with 180 eggs per replication. The results of this study showed the average survival rate of embryo eggs chicken Ross was 97,68\%, duration of hatching is 475,59 hours and unhatched by $8,48 \%$. The temperature deserved in the study was $36,88-36,97^{\circ} \mathrm{C}$ and humidity was $68,16-68,42 \%$. Based on the analysis showed that the eggs position did not how a significant effect $(P>0,05)$ on survival rate of embryo, duration of hatching and unhatched. The conclusion of this research was the difference of eggs position in the incubator provides optimal heat, so that the temperature and humidity produced are evenly distributed.
\end{abstract}

Keywords: Duration of hatching, Egg position, Survival rate of embryo, Unhatched 
Prosiding Seminar Nasional Pembangunan danPendidikanVokasiPertanian

Politeknik Pembangunan PertanianManokwari, 31Juli 2021

e ISSN : 2774-1982

DOI : https://doi.org/10.47687/snppvp.v2i1.185

\section{PENDAHULUAN}

Sistem penetasan terdiri dari penetasan alami dan buatan. Penetasan buatan merupakan suatu proses menetaskan telur sampai menjadi individu baru dengan bantuan mesin tetas. Menurut Subiharta dan Yuwanta (2012) prinsip penetasan dengan mesin tetas adalah menyesuaikan suhu, kelembapan dan pemutaran telur yang sesuai untuk perkembangan embrio. Penggunaan mesin tetas, secara umum berfungsi untuk menetaskan telur dalam jumlah besar dan memperoleh hasil penetasan yang optimal. Keberhasilan dalam penetasan buatan didukung dengan manajemen penetasan yang baik, seperti manajemen penangganan telur tetas yang meliputi penerimaan telur tetas, seleksi telur tetas, fumigasi dan penyimpanan telur tetas, serta manajemen mesin tetas dengan memperhatikan pengaturan suhu dan kelembapan dalam mesin tetas secara tepat.

Suhu dan kelembapan penting diperhatikan karena memiliki pengaruh dalam menstimulir perkembangan embrio selama proses penetasan. Suhu dan kelembapan yang tinggi menyebabkan embrio lemah bahkan mati akibat dehidrasi, sedangkan suhu dan kelembapan yang rendah menyebabkan embrio tidak berkembang secara maksimal. Menurut Mulyantini (2010) suhu penetasan yang disarankan untuk periode setter berkisar antara $37,2-38,2^{\circ} \mathrm{C}$ dan untuk periode pertengahan penetasan sekitar $37-37,5^{\circ} \mathrm{C}$. Menurut Paimin (2011) kelembapan yang optimal untuk telur saat awal penetasan sekitar 52-55\% dan menjelang menetas sekitar 60-70\%.

Letak telur merupakan posisi penempatan telur dalam mesin tetas pada bagian rak atas, rak tengah dan rak bawah. Diduga letak telur yang berbeda dalam mesin tetas menyebabkan suhu dan kelembapan yang dihasilkan tidak menyebar secara merata. Dengan demikian perbedaan letak telur dalam mesin tetas dapat memengaruhi persentase daya hidup embrio, lama menetas dan meningkatkan persentase gagal menetas. Persentase gagal menetas yang tinggi menyebabkan daya tetas telur menjadi rendah, sehingga dapat menurunkan produktifitas untuk mendapatkan bibit baru. Berdasarkan permasalahan tersebut dilakukannya penelitian ini, penyusun ingin mengetahui pengaruh letak telur dalam mesin tetas terhadap persentase daya hidup embrio, lama menetas dan gagal menetas.

\section{METODE}

Penelitian dilaksanakan di PT. Super Unggas Jaya Unit Hatchery Solo, Jawa Tengah pada bulan Januari 2021. Alat dan bahan yang digunakan dalam penelitian ini adalah mesin tetas otomatis tipe Pearl 22, data logger, candler, timbangan digital, 
Prosiding Seminar Nasional Pembangunan danPendidikanVokasiPertanian

Politeknik Pembangunan PertanianManokwari, 31Juli 2021

e ISSN : 2774-1982

DOI : https://doi.org/10.47687/snppvp.v2i1.185

sumber energi listrik, tray, 2.700 butir telur ayam strain Ross umur induk 43-45 minggu. Perlakuan dalam penelitian adalah letak telur yang berbeda dalam mesin tetas $(\mathrm{P})$ :

$\mathrm{P}_{1}=$ Letak telur dalam mesin tetas bagian rak atas

$\mathrm{P}_{2}=$ Letak telur dalam mesin tetas bagian rak tengah

$\mathrm{P}_{2}=$ Letak telur dalam mesin tetas bagian rak bawah

Penelitian menggunakan Rancangan Acak Lengkap, setiap perlakuan diulang 5 kali dan tiap ulangan berisi 180 butir telur. Seluruh data yang diperoleh dari percobaan dianalisis menggunakan sidik ragam pada taraf 5\%. Jika suatu perlakuan berpengaruh nyata pada suatu peubah $(\mathrm{P}<0,05)$, maka dilanjutkan uji BNT (Beda Nyata Terkecil) pada taraf 5\%. Pelaksanaan penelitian dimulai dari seleksi telur, pengumpulan telur tetas, prewarming, memasukkan telur dalam ruang setter, peletakan data logger, pengontrolan harian, candling, memasukkan telur dalam ruang hattcher dan pull chick.

Variabel yang diamati adalah:

1. Persentase Daya Hidup Embrio

Perhitungan daya hidup embrio dilakukan dengan cara menghitung jumlah telur yang fertil pada umur 19 hari penetasan, dihitung menggunakan rumus menurut Nafiu et al. (2014) sebagai berikut:

Daya Hidup Embrio $=\frac{\text { Jumlah telur yang hidup }}{\text { Jumlah telur yang fertil }} \times 100 \%$

2. Lama Menetas

Lama menetas diperoleh dengan menghitung waktu dari hari pertama telur masuk dalam penetasan sampai telur menetas dan DOC keluar dari kerabang dalam satuan jam dan menit (Manggiasih et al., 2015).

3. Presentase Gagal Menetas

Gagal menetas dihitung dengan rumus sebagai berikut:

Gagal Menetas $=\frac{\text { Jumlah telur tidak menetas }}{\text { Jumlah telur yang ditetaskan }} \times 100 \%$

\section{HASIL DAN PEMBAHASAN}

Hasil analisis data daya hidup embrio, lama menetas dan gagal menetas dalam mesin tetas pada letak yang berbeda dapat dilihat pada Tabel 1 . 
Prosiding Seminar Nasional Pembangunan danPendidikanVokasiPertanian

Politeknik Pembangunan PertanianManokwari, 31Juli 2021

e ISSN : 2774-1982

DOI : https://doi.org/10.47687/snppvp.v2i1.185

Tabel 1. Persentase daya hidup embrio, lama menetas dan persentase gagal menetas

\begin{tabular}{lccc}
\hline \multicolumn{1}{c}{ Letak Telur } & $\begin{array}{c}\text { Daya Hidup Embrio } \\
(\%)\end{array}$ & $\begin{array}{c}\text { Lama Menetas } \\
(\mathrm{Jam})\end{array}$ & $\begin{array}{c}\text { Gagal Menetas } \\
(\%)\end{array}$ \\
\hline Rak Atas & 97,11 & 480,05 & 9,11 \\
Rak Tengah & 97,90 & 473,67 & 8,44 \\
Rak Bawah & 98,04 & 475,59 & 7,88 \\
\hline Rata-rata & 97,68 & 475,59 & 8,48 \\
\hline
\end{tabular}

\section{Daya Hidup Embrio}

Rata-rata persentase daya hidup embrio pada penelitian ini yaitu 97,68\% (Tabel 1). Hasil persentase pada penelitian ini lebih tinggi dibandingkan dengan penelitian Fadwiwati et al. (2020) yang memperoleh daya hidup embrio ayam SenSi-1 Agrinak sebesar $87,72 \%$. Indrawati et al. (2015) menyatakan bahwa rata-rata daya hidup embrio persilangan telur ayam ras dengan ayam tolaki hanya diperoleh sebesar 92,18\%. Persentase daya hidup embrio yang tinggi menunjukkan hasil penelitian sudah baik dan mesin tetas berfungsi secara maksimal dengan menghasilkan panas yang optimal.

Berdasarkan analisis sidik ragam, perlakuan letak telur dalam mesin tetas tidak berpengaruh nyata $(\mathrm{P}>0,05)$ terhadap persentase daya hidup embrio. Hal ini diduga karena suhu dan kelembapan dalam mesin tetas telah tersebar secara merata pada bagian rak atas, rak tengah dan rak bawah. Kondisi mesin tetas otomatis telah dilengkapi dengan lampu pijar dan seperangkat alat yang disebut thermostat (termoregulator). Menurut Marhiyanto (2000), termoregulator berfungsi mengatur suhu dan kelembapan di dalam mesin tetas secara otomatis. Apabila suhu dalam mesin tetas melebihi batas yang ditentukan, maka termoregulator akan memutus arus listrik dan lampu menjadi padam. Sebaliknya jika suhu dalam mesin tetas rendah, maka termoregulator akan menyambung arus listrik agar lampu menyala. Dengan demikian, suhu dan kelembapan dalam mesin tetas tetap stabil.

Rata-rata suhu yang diperoleh pada penelitian ini adalah $36,88^{\circ} \mathrm{C}$ (Gambar 1.) dan kelembapan sebesar 68,16\% (Gambar 2.). Hasil ini menunjukkan bahwa suhu dan kelembapan yang terdapat di dalam mesin tetas sudah baik. Menurut Nasruddin dan Arif (2014) suhu penetasan yang disarankan berkisar antara $36-39^{\circ} \mathrm{C}$, sedangkan kelembapan relatif antara $55-70 \%$.

Suhu penetasan selama pengamatan letak telur yang berbeda dalam mesin tetas disajikan pada gambar dibawah ini: 
Prosiding Seminar Nasional Pembangunan danPendidikanVokasiPertanian

Politeknik Pembangunan PertanianManokwari, 31Juli 2021

e ISSN : 2774-1982

DOI : https://doi.org/10.47687/snppvp.v2i1.185

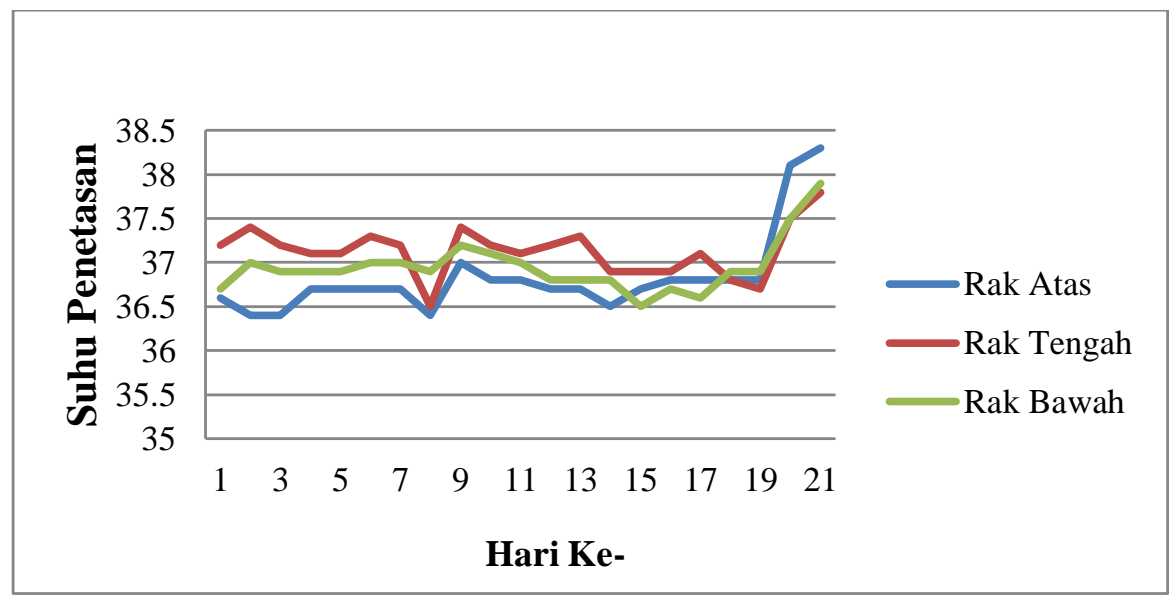

Gambar 1. Grafik suhu penetasan

Hasil pengamatan kelembapan mesin tetas pada letak telur yang berbeda sebagai berikut:

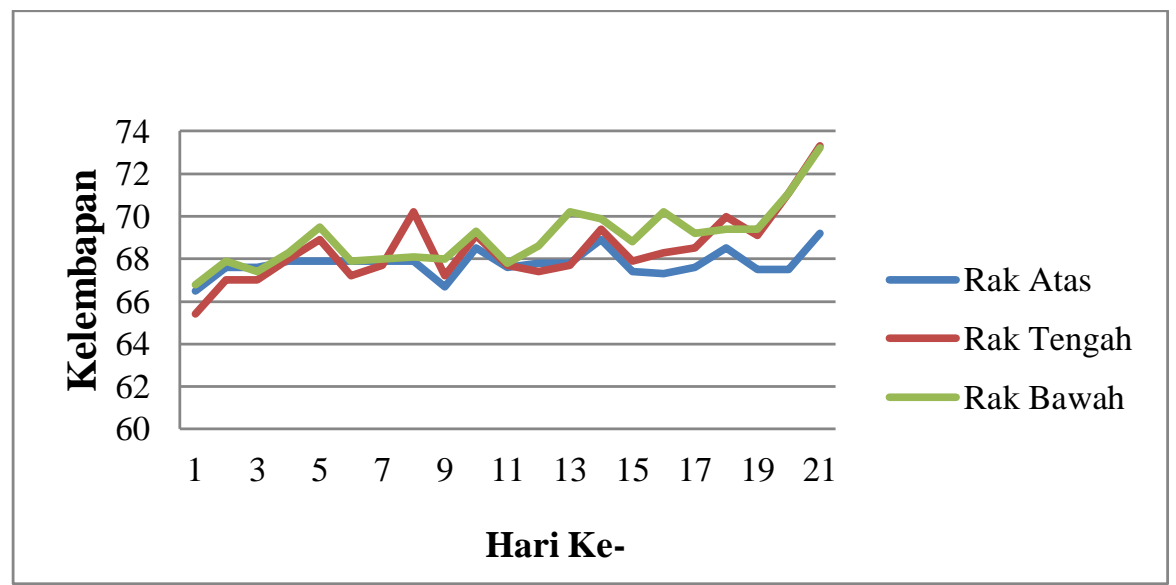

Gambar 2. Grafik kelembapan dalam mesin tetas

Suhu dan kelembapan memengaruhi proses perkembangan embrio di dalam telur, sehingga penangganan telur tetas selama penetasan harus dilakukan secara tepat. Menurut Daulay et al. (2008), suhu dalam mesin tetas yang tidak merata menyebabkan embrio akan lengket pada salah satu sisi kerabang, sehingga embrio akan mati. Suhu yang rendah dapat memperlambat pertumbuhan organ-organ pada telur, sehingga embrio tidak berkembang secara proporsional. Namun, suhu yang tinggi berdampak buruk bagi DOC yang dihasilkan. Embrio di dalam telur mengalami dehidrasi sehingga DOC menjadi lemah dan menyebabkan kekerdilan serta meningkatnya persentase mortalitas (Hartono dan Isman, 2010). Penyebaran kelembapan dalam mesin tetas yang rendah menyebabkan embrio mengalami dehidrasi, sedangkan kelembapan yang tinggi menyebabkan posisi embrio tidak teratur, sehingga proses pernapasan terganggu dan penyerapan albumen 
Prosiding Seminar Nasional Pembangunan danPendidikanVokasiPertanian

Politeknik Pembangunan PertanianManokwari, 31Juli 2021

e ISSN : 2774-1982

DOI : https://doi.org/10.47687/snppvp.v2i1.185

menjadi tidak optimal yang mengakibatkan embrio menempel pada membran dinding telur.

\section{Lama Menetas}

Hasil penelitian menunjukkan bahwa rata-rata perlakuan letak telur yang berbeda terhadap lama menetas sebesar 475,59 jam atau 19,82 hari (Tabel 1). Berdasarkan hasil penelitian yang diperoleh, kecepatan lama menetas sudah bagus. Hasil penelitian ini lebih cepat dibandingkan dengan penelitian Herlina et al. (2016) yang menyatakan bahwa lama menetas ayam Merawang tercepat sebesar 19,95 hari (478,8 jam ) dan 20,30 hari (487,2 jam) untuk penetasan terlama. Nafiu et al. (2014) melaporkan bahwa rata-rata lama penetasan ayam Merawang sebesar 20,07 hari (481,68 jam).

Berdasarkan analisis sidik ragam, letak telur tidak berpengaruh nyata $(P>0,05)$ terhadap lama menetas. Hal ini dikarenakan letak telur dalam mesin tetas baik bagian rak atas, tengah dan bawah memiliki penyebaran panas yang optimal, sehingga suhu dan kelembapannya relatif merata. Rata-rata suhu selama 21 hari penetasan yaitu $36,97^{\circ} \mathrm{C}$ (Gambar 1.) dan kelembapan sebesar 68,42\% (Gambar 2). Parkust dan Moutney (1998) menyatakan bahwa suhu yang baik untuk penetasan adalah $36-40^{\circ} \mathrm{C}$, sedangkan kelembapan berkisar antara 60-79\%. Embrio tidak toleran terhadap perubahan suhu dan kelembapan yang drastis. Sesuai dengan pendapat Soesanto (2002) yang menyatakan bahwa lama tetas sangat dipengaruhi oleh lingkungan dalam inkubator. Suhu yang konstan selama proses penetasan akan mempercepat waktu penetasan telur. Manggiasih et al. (2015) menambahkan bahwa suhu yang konstan memengaruhi respon embrio dalam proses pertumbuhan dibandingkan dengan suhu tinggi, kenaikan suhu yang singkat menyebabkan embrio menyesuaikan diri terhadap fluktuasi perubahan suhu melalui penurunan tingkat pertumbuhan dan perkembangan. Lourens et al. (2011) melaporkan bahwa peningkatan suhu yang tidak tepat dapat menyebabkan lambatnya kematangan jaringan.

Sementara itu, kelembapan memengaruhi percepatan laju perkembangan embrio akibat laju metabolisme yang berlangsung lebih cepat. Hal ini karena kelembapan mesin tetas berperan mempertahankan cairan di dalam telur selama proses penetasan dan membantu memecahkan kulit telur saat akan menetas, sehingga DOC mudah melepaskan cangkang telurnya (Kurtini dan Riyanti, 2014). Menurut Salahi et al. (2011) telur yang lambat menetas dikarenakan proses metabolisme lemak yang belum sempurna sehingga membutuhkan waktu lebih lama untuk proses injeksi lipid. 
Prosiding Seminar Nasional Pembangunan danPendidikanVokasiPertanian

Politeknik Pembangunan PertanianManokwari, 31Juli 2021

e ISSN : 2774-1982

DOI : https://doi.org/10.47687/snppvp.v2i1.185

\section{Gagal Menetas}

Berdasarkan Tabel 1, rata-rata persentase gagal menetas dari telur pada letak yang berbeda dalam mesin tetas adalah sebesar $8,48 \%$. Hasil ini lebih rendah dibandingkan dengan penelitian dari Siregar et al. (2013) yang mendapatkan daya tetas ayam kampung sebesar $82,5 \%$, dengan persentase gagal menetas sebesar $17,5 \%$. Bahkan jauh lebih rendah dari hasil penelitian Siti et al. (2017) yang memperoleh persentase daya tetas telur ayam ras petelur $80,2 \%$, dengan persentase gagal menetas pada telur ayam ras petelur sebesar 19,8\%. Persentase gagal menetas yang rendah menunjukkan hasil penelitian sudah baik, karena rendahnya persentase gagal menetas menyebabkan daya tetasnya tinggi, sebaliknya apabila persentase gagal menetas tinggi maka daya tetasnya rendah.

Hasil analisis sidik ragam menunjukkan bahwa perlakuan letak telur dalam mesin tetas tidak berpengaruh secara nyata $(\mathrm{P}>0,05)$ terhadap persentase gagal menetas. Hal ini dikarenakan suhu dan kelembapan selama penetasan pada perlakuan letak telur bagian rak atas, rak tengah maupun rak bawah tidak jauh berbeda dan merata dengan baik, sehingga gagal menetas yang dihasilkan relatif sama. Rata-rata suhu dan kelembapan selama penetasan pada perlakuan letak telur bagian rak atas memperoleh suhu $36,82^{\circ} \mathrm{C}$ dan kelembapan $67,79 \%$, perlakuan letak telur bagian rak tengah memperoleh suhu $37,13^{\circ} \mathrm{C}$ dan kelembapan $68,48 \%$, sedangkan perlakuan letak telur bagian rak bawah memperoleh suhu $36,95^{\circ} \mathrm{C}$ dan kelembapan sebesar $69 \%$. Suhu dan kelembapan yang dihasilkan pada penelitian ini tidak jauh berbeda dengan laporan Kurtini et al. (2010), bahwa suhu untuk penetasan ayam yaitu sekitar $98,6-102,75^{\circ} \mathrm{F}$ $\left(37,6^{\circ} \mathrm{C}\right)$ dan kelembapannya sekitar 5560\%.

Faktor yang memengaruhi gagal menetas dalam penelitian ini adalah kematian awal embrio karena pertumbuhannya yang tidak optimal, kegagalan di akhir masa penetasan yang disebabkan oleh pengeringan selaput telur, sehingga embrio tidak menetas serta kegagalan DOC dalam melakukan pipping. Hal ini sejalan dengan pendapat Setiadi (2000) yang menyatakan bahwa kegagalan dalam proses penetasan terjadi pada akhir masa penetasan, disebabkan oleh pengeringan selaput pada pertumbuhan embrio yang tidak sempurna, sehingga embrio tidak menetas dan masih terdapat dalam kerabang telur. Menurut Sudrajat (2001), kegagalan dalam proses penetasan telur disebabkan oleh faktor kualitas dari mesin tetas yang mengakibatkan suhu di dalam mesin tetas tidak 
Prosiding Seminar Nasional Pembangunan danPendidikanVokasiPertanian

Politeknik Pembangunan PertanianManokwari, 31Juli 2021

e ISSN : 2774-1982

DOI : https://doi.org/10.47687/snppvp.v2i1.185

stabil, udara dalam mesin tetas terlalu kering dan kesalahan dalam manajemen mesin tetas.

\section{KESIMPULAN DAN SARAN}

Berdasarkan hasil penelitian, diambil kesimpulan bahwa perbedaan perlakuan letak telur dalam mesin tetas menyediakan panas yang optimal, sehingga suhu dan kelembapan yang dihasilkan tersebar secara merata baik pada bagian rak atas, rak tengah dan rak bawah.

\section{UCAPAN TERIMA KASIH}

Peneliti mengucapkan terima kasih kepada PT. Super Unggas Jaya Unit Hatchery Solo dan Fakultas Pertanian Universitas Tidar atas izin yang diberikan untuk melakukan penelitian.

\section{DAFTAR PUSTAKA}

Daulay, A.H., S. Aris \& A. Salim. (2008). Pengaruh umur dan frekuensi pemutaran terhadap daya tetas dan mortalitas telur ayam arab (Galus turcisus). Jurnal Agribisnis Peternakan. Vol.1, No. 4.

Fadwiwati, A.Y., Surya, Soimah, M., Rosdiana, Amin, N., \& Saenab, A. (2020). Daya tunas dan daya tetas telur ayam SenSi-1 Agrinak di Balai Pengkajian Teknologi Pertanian (BPTP) Gorontalo. Prosiding Seminar Nasional Teknologi Peternakan dan Veteriner Virtual. Hal. 546-554.

Hartono, T \& Isman. (2010). Kiat sukses menetasakan telur ayam. Agromedia Pustaka. Yogyakarta.

Herlina, B., T. Karyono, R. Novita \& P. Novantoro. (2016). Pengaruh lama penyimpanan telur ayam Merawang (Gallus gallus) terhadap daya tetas. Jurnal Sain Peternakan Indonesia. Vol. 11. No. 1.

Indrawati, E., T. Saili, \& S. Rahadi. (2015). Fertilitas, Daya hidup embrio, daya tetas dan bobot tetas telur ayam ras hasil inseminasi buatan dengan ayam tolaki. Jurnal Ilmu dan Teknologi Peternakan Tropis. Vol. 1., No. 3, 10-18.

Kurtini, T., R. Riyanti \& D. Seotinova. (2010). Teknologi penetasan unggas. Penuntun praktikum. Universitas Lampung. Lampung.

Kurtini, T \& R. Riyanti. (2014). Teknologi Penetasan Edisi II. AURA. Bandar Lampung.

Lourens, A., R. Meijerhof, B. Kemp, \& H. van den Brand. (2011). Energy Partitioning During Incubation and Consequences for Embryo Temperature: A Theoretical Approach. Poultry Science 90:516-523. 
Prosiding Seminar Nasional Pembangunan danPendidikanVokasiPertanian

Politeknik Pembangunan PertanianManokwari, 31Juli 2021

e ISSN : 2774-1982

DOI : https://doi.org/10.47687/snppvp.v2i1.185

Manggiasih, N.N., D. Garnida, \& A. Mushawwir. (2015). Susut Telur, Lama dan Bobot Tetas Itik Lokal (Anas sp.) Berdasarkan Pola Pengaturan Temperatur Mesin Tetas. Fakultas Peternakan Universitas Padjadjaran. Bandung

Marhiyanto, B. (2000). Sukses beternak ayam arab. Difa Publisher. Jakarta.

Nafiu, L., M. Rusdin., \& A. S. Aku. (2014). Daya tetas dan lama menetas telur ayam Tolaki pada mesin tetas dengan sumber panas yang berbeda. Universitas Halu Oleo. JITRO. Vol. 1 (1).

Nasruddin \& Z. Arif. (2014). Analisa perubahan temperatur dan kelembapan relatif pada inkubator peetas telur yang menggunaan fan dan tidak menggunakan fan. Journal Ilmiah JURUTRA. Vol. 01, No. 01: 031-035.

Paimin, F.B. (2011). Membuat dan mengelola mesin tetas. Penebar Swadaya. Jakarta.

Parkust, C. R \& Moutney. (1998). Poultry meat and egg production. Van Nostrand Reinhold. New York.

Salahi, A., S.N. Mousavir, F. Fourodi, M.M. Khasibi, \& M. Norozi. (2011). Effect of in ovo Injection of Butyric Acid in Broiler Breeder Eggs on Hatching Parameters, Chick Quality and Performance. Global Veteriner 7 (5) 468-477.

Setiadi, P. (2000). Pengaruh indeks bentuk telur terhadap persentase kematian embrio, gagal tetas dan dod cacat pada itik tegal yang diseleksi. Jurnal Animal Production. Vol. 2. No. $1: 80-86$.

Siregar, R.P., Nurzainah, G., \& Zulfikar, S. (2013). Pemanfaatan gas bio sebagai sumber energi panas dalam penetasan telur ayam kampung. J. Peternakan Integratif. Vol. 1. No. $3: 314-325$.

Siti, A., N.A. Lia \& R. Ugik. (2017). Manajemen penetasan telur ayam di PT. X di Jombang. Jurnal Inovasi Penelitian (JIP). Vol. 1., No. 8, 63-66.

Soesanto. (2002). Pengaruh frekuensi pemutaran telur terhadap daya tetas dan bobot badan DOC ayam kampung. Jurnal Agribisnis Peternakan. 2:101-105.

Subiharta \& D.M. Yuwana. (2012). Pengaruh penggunaan bahan tempat air dan letak telur di dalam mesin tetas yang berpemanas listrik pada penetasan itik Tegal. Seminar Nasional Kedaulatan Pangan dan Energi. Fakultas Pertanian 7:2. 